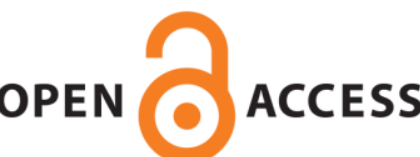

OPEN ACCESS

UWS Academic Portal

\title{
Learning from loss for professionals and parents
}

McEwan, Tom

Published in:

British Journal of Midwifery

DOI:

10.12968/bjom.2019.27.11.677

Published: 02/11/2019

Document Version

Peer reviewed version

Link to publication on the UWS Academic Portal

Citation for published version (APA):

McEwan, T. (2019). Learning from loss for professionals and parents. British Journal of Midwifery, 27(11), 677677. https://doi.org/10.12968/bjom.2019.27.11.677

\section{General rights}

Copyright and moral rights for the publications made accessible in the UWS Academic Portal are retained by the authors and/or other copyright owners and it is a condition of accessing publications that users recognise and abide by the legal requirements associated with these rights.

Take down policy

If you believe that this document breaches copyright please contact pure@uws.ac.uk providing details, and we will remove access to the work immediately and investigate your claim. 
"This document is the Accepted Manuscript version of a Published Work that appeared in final form in British Journal of Midwifery, copyright (C) MA Healthcare, after peer review and technical editing by the publisher. To access the final edited and published work see https://doi.org/10.12968/ bjom.2019.27.11.677." 


\section{BJM Editorial- Tom McEwan.}

The importance of learning from loss for professionals and parents.

On the $10^{\text {th }}$ October 2019, the first annual report from the Perinatal Mortality Review Tool (PMRT) was published, entitled 'Learning from Standardised Reviews When Babies Die' (Chepkin et al, 2019). This first national report, delivered in collaboration with MBRRACEUK, is the culmination of a review of 1,500 cases where babies have died. It is driven by a two-fold ambition; to ensure that every parent will know as much as possible about why their baby died, and to support professionals to undertake objective, standardised and critically reflective reviews following these deaths. This report supports both ambitions by sharing the learning from this process at both a local and national level, with the aim of preventing future deaths in similar circumstances, and suggesting improvements to existing services.

The report highlights several key findings and recommendations from this initial review period. Firstly, the majority of cases were not reviewed by an appropriate group of staff representing the variety of roles within the multidisciplinary, perinatal team. In some instances, cases were reviewed by only one or two staff members, and fewer than $10 \%$ of reviews included an external member who could provide the 'fresh eyes' perspective. Additionally, the finding that in $41 \%$ of cases involving a neonatal death, no neonatologist was participant in the review, was both astonishing and alarming as a former neonatal mid wife myself. This does not demonstrate a robust multidisciplinary process.

Furthermore, the activity of reviewing such cases was not routinely captured in the activity plans of staff, support for parents through the process was inadequately resourced and administrative support for the review groups was only recorded within $11 \%$ of those reported. As such, clear guidance on the composition and function of PMRT review groups has been provided.

Secondly, although it was identified that $84 \%$ of parents were told a review was being conducted into the death of their baby, fewer than half of all parents expressed any concern or posed questions regarding the care they had received during pregnancy or childbirth, or around the time of their loss. Whether this is a true reflection of the parents views at these times, or simply a sign of them not feeling able to ask questions or feeling engaged with the process, the focus should be directed on the latter with encouragement directed at staff caring for bereaved parents to ensure they are given ample opportunities to raise questions or discuss any concerns.

Lastly, the report highlights issues identified with both the care provided and the presence of other contributory factors. The PMRT utilises a four-level system for grading the care provided which ranges from a classification of no issues identified, through issues that would not have changed the outcome, may have changed the outcome or were likely to have changed the outcome. Although $90 \%$ of reviews identified at least one issue with care provided before grading, only a small subset indicated that different care provided may, or would, have resulted in a different outcome. Most of these related to pregnancy care and included carbon monoxide monitoring, access to smoking cessation, fetal growth surveillance, management of reduced fetal movements and assessment of maternal aspirin need during pregnancy. Monitoring failures were also identified, from poor thermal management throughout neonatal care, monitoring during labour and poor documentation 
following resuscitation. Of particular importance to us all as maternity care professionals were the contributory factors identified which included absence of, or failure to adhere to, guidelines and protocols, poor interprofessional communication and the impact of conflicting organisational priorities.

As a midwifery lecturer, one of the most frequent concerns raised by my students is their fear of a mother or baby dying in their care, especially when they become a newly qualified midwife. This is a difficult fear for my colleagues and I to try an allay, despite our reassurances that giving birth within the UK is largely safe and without adverse complications. I believe that much of this fear relates to their perceptions of the investigation that will follow such an event, especially if this identifies that the death may have been avoidable, as a culture of blame still pervades many areas of the health service. However, this report highlights that only a small number of cases reviewed were identified as potentially avoidable, reaffirming the importance of a rigorous, transparent and honest review of these cases to identify actions that could be taken to improve future care provision. In order that we can learn together from these deaths, the importance of their participation in these reviews, as well as including parents, cannot be overstated.

Samantha Chepkin, Sarah Prince, Tracey Johnston, Thomas Boby, Miguel Neves et al. Learning from Standardised Reviews When Babies Die. National Perinatal Mortality Review Tool: First Annual Report. Oxford: National Perinatal Epidemiology Unit. 2019. 